\title{
Uso de adoçantes dietéticos por usuários da Atenção Básica no Sistema Único de Saúde, Brasil
}

\section{Use of dietary sweeteners by SUS primary health care users in Brazil}

\author{
Bianca Maria Santos da Paz* iD \\ Ediná Alves Costa
}

Instituto de Saúde Coletiva, Universidade Federal da Bahia (UFBA), Salvador, BA, Brasil

\section{*E-mail: bpaz@ufba.br}

\section{RESUMO}

Introdução: O uso de adoçantes dietéticos vem aumentando nas últimas décadas. Considerando possíveis riscos à saúde, tais produtos encontram-se sob vigilância sanitária. Objetivo: Caracterizar o uso de adoçantes dietéticos pela população usuária da Atenção Básica no Sistema Único de Saúde/Brasil. Método: Estudo transversal, exploratório, com utilização do banco de dados da Pesquisa Nacional sobre Acesso, Utilização e Promoção do Uso Racional de Medicamentos (PNAUM) - Serviços. Da amostra de 8.803 indivíduos adultos entrevistados pela PNAUM na Atenção Básica, em amostra de municípios das regiões do Brasil, aqueles autodeclarados usuários de adoçantes dietéticos formaram a subamostra da população deste estudo (1.802 usuários de adoçantes dietéticos), caracterizada segundo variáveis demográficas, socioeconômicas, estilo de vida e condições de saúde. Os dados foram analisados com o SPSS, versão 22 e análise de associação estatística com o teste do Qui-quadrado, com nível de significância de $p<0,05$. Resultados: Vinte e um por cento dos entrevistados pela PNAUM declararam usar adoçantes dietéticos. 0 uso distribuiu-se pelas regiões com diferenças estatísticas significativas, maior proporção no Sul e menor no Centro-Oeste. A maior proporção de uso foi por mulheres, o uso foi maior nas faixas etárias mais elevadas em ambos os sexos, na escolaridade fundamental, estado civil casados, classe econômica $\mathrm{C}$ e autoavaliação da saúde declarada boa, seguida de nem ruim nem boa. Quanto às dietas investigadas, as mulheres também predominaram, assim como em referência a ter diabetes e depressão, enquanto entre homens predominaram hipertensão e dislipidemia. Conclusões: Constatou-se largo uso de adoçantes dietéticos entre os usuários da Atenção Básica/SUS. Considerando que estudos apontam possíveis malefícios à saúde relacionados a esses produtos, ações de regulação e vigilância sanitária orientadas ao seu uso racional são recomendadas.

PALAVRAS-CHAVE: Adoçantes Dietéticos; Riscos à Saúde; Vigilância Sanitária

\section{ABSTRACT}

Introduction: Dietary sweeteners have been increasingly used in recent decades. Due to their potential health risks, such products are under health surveillance. Objective: To characterize the use of dietary sweeteners by SUS primary healthcare users in Brazil. Method: This is a cross-sectional, exploratory study drawn on the PNAUM - Services database. Out of the sample of 8,803 adults interviewed by PNAUM among primary care users in a sample of municipalities in Brazilian regions, a subsample of those self-declared users of dietary sweeteners (1,802 adults) was characterized according to demographic, socioeconomic, lifestyle and health status variables. Data were analyzed using SPSS v.22 software and the statistical association was determined by the chi-square test, with a significance level of $p<0.05$. Results: $21.0 \%$ of those interviewed by PNAUM stated they used dietary sweeteners. There were statistically significant differences in their use across regions, with the highest proportion in the South and the lowest in the Midwest. Women were found to be the highest users, and, for both sexes, the use was higher in the older age groups as well as among those who were married, with elementary schooling, in 
the "C" economic class and whose self-rated health was good, followed by those with neither good nor bad self-rated health. Women were also found to prevail among the followers of the investigated diets and among those with diabetes and depression, whereas among men those with hypertension and dyslipidemia were more prevalent. Conclusions: A wide use of diet sweeteners was shown among SUS primary healthcare users. Since studies point to potential health-damaging effects of such products, the need for regulation and health surveillance actions towards their rational use is urged.

KEYWORDS: Dietary Sweeteners; Health Risks; Health Surveillance

\section{INTRODUÇÃO}

O Brasil vem experimentando, nas últimas três décadas, importantes transformações no seu perfil epidemiológico, com significativas mudanças nas taxas de morbimortalidade, em contextos de desenvolvimento econômico-social, avanços nas políticas sociais e de saúde e mudanças no estilo de vida. As doenças crônicas não transmissíveis (DCNT) respondem por cerca de $75 \%$ das mortes e perda de qualidade de vida, mas as taxas dessas doenças vêm declinando em função de ações governamentais específicas ${ }^{1}$, inclusive com acordos com a indústria de alimentos para que reduzam o teor de sal em alimentos processados e eliminem as gorduras trans ${ }^{2}$.

Observa-se, neste contexto, crescimento do interesse por estética e culto ao corpo que leva pessoas a se submeterem a dietas restritivas $^{3}$, nem sempre sob orientação profissional ${ }^{4}$, incluindo uso de adoçantes e outros produtos dietéticos. Conforme a Associação Brasileira de Indústrias de Alimentos Dietéticos e para Fins Especiais (Abiad), em 2004, estimava-se que existiam cerca de 120 indústrias dedicadas à produção de alimentos diet e light, representando cerca de $3 \%$ a $5 \%$ de todos os alimentos vendidos no país, movimentando algo em torno de 3 bilhões de dólares ${ }^{5}$. Em 2009, esse valor já estava triplicado6.

Apesar da ampla utilização dos adoçantes dietéticos e de sua regulamentação sanitária, pesquisadores afirmam não haver, ainda, informações definitivas de sua inocuidade para a saúde dos consumidores diretos ou indiretos - lactentes de mães ou fetos de gestantes em uso desses adoçantes ${ }^{7,8}$. Segundo Bruyère et al. ${ }^{9}$, não foram identificados benefícios ou riscos relacionados ao consumo de edulcorantes intensos durante a gravidez, em termos de saúde materna, parâmetros obstétricos ou de saúde do recém-nascido.

Autores sugerem efeitos supostamente prejudiciais ao organismo ${ }^{10,11,12}$, o que desperta a atenção para possíveis riscos no uso dos adoçantes dietéticos. Suez et al. ${ }^{12}$ atribuíram a esses adoçantes o aumento do risco de intolerância à glicose em humanos e ratos, mediada pela modulação da composição e função da microbiota intestinal pelos adoçantes. Kimata ${ }^{13}$ relatou a ocorrência de forte reação alérgica em crianças após o consumo da folha da estévia. Há contraindicação do aspartame para portadores de fenilcetonúria (PKU) ${ }^{14}$. Gardner et al. ${ }^{15}$ observaram que o aumento no consumo dos produtos contendo adoçante dietético não se refletiu na redução do uso de produtos adoçados com açúcar, acreditando haver um efeito compensatório ou mudanças no controle do apetite.
Organismos responsáveis pela proteção da saúde - Organização Mundial da Saúde (OMS), Food and Drug Administration, Autoridade Europeia para Segurança Alimentar e Agência Nacional de Vigilância Sanitária (Anvisa) - não fazem objeção ao uso de adoçantes dietéticos, mas recomendam moderação, respeito aos limites diários estabelecidos pela OMS e alternância do tipo utilizado $^{16}$. Com base no código de ética profissional, o Conselho Federal de Nutricionistas (CFN) recomenda, para a prescrição, análise técnico-científica, respeito aos limites de ingestão diária aceitável (IDA) e observação da indicação clínica ${ }^{17}$.

Considerando possíveis riscos à saúde, tais produtos estão sob vigilância sanitária, cujas ações orientam-se à avaliação e ao controle de riscos relacionados a produtos, às tecnologias e aos serviços de saúde e de interesse da saúde ${ }^{18}$.

Devido à natureza essencialmente preventiva da função que exerce, a vigilância sanitária lida tanto com o conceito de risco epidemiológico, enquanto probabilidade de ocorrência de um evento em coletivos humanos expostos a determinado fator de risco e por certo tempo de observação, quanto com o risco como possibilidade de ocorrência de eventos que poderão provocar danos à saúde, situações em que muitas vezes não se pode precisar qual o evento e até mesmo se algum ocorrerá19.

Em que pese o consumo de adoçantes vir sendo mundialmente estudado, até 2016 apenas nove países apresentavam dados científicos a nível nacional, sobre o uso desses produtos dieté$\operatorname{ticos}^{20}$. No Brasil, onde os produtos dietéticos vêm sendo largamente aceitos e consumidos, foi realizado um inquérito de base populacional $2008-2009^{20}$, que encontrou uma prevalência de uso de adoçantes artificiais estimada em 7,6\% e de uso concomitante com açúcar em 5,1\%. Aproximadamente $20,0 \%$ dos idosos e indivíduos no maior quartil de renda eram os maiores consumidores de adoçantes artificiais, no país.

Identificou-se dois outros estudos sobre o uso de adoçantes entre adultos com 20 anos ou mais: Zanini et al. ${ }^{21}$, na cidade de Pelotas, encontrou prevalência de uso maior em mulheres, pessoas com idade maior que 29 anos, pele clara, maior preferência por sacarina e ciclamato e $98 \%$ de uso de adoçantes na forma líquida. Geraldo e Silva ${ }^{22}$, em estudo realizado com amostra constituída por funcionários de universidades públicas do estado de São Paulo, estimaram prevalência maior entre mulheres de 40 a 59 anos, casados e pessoas com mais de 12 anos de estudo, renda de cinco a 10 salários mínimos e praticantes de atividades 
físicas duas a três vezes por semana. Concluíram que o perfil do consumidor de adoçantes e alimentos dietéticos é especialmente de pessoas com excesso de peso ou dificuldades para manter o peso, não diabéticos e não hipertensos.

Tais achados suscitaram o seguinte questionamento: como se caracteriza o uso de adoçantes dietéticos na população usuária da Atenção Básica ( $A B$ ) no Sistema Único de Saúde (SUS)? Assim, definiu-se como objetivo deste estudo caracterizar o perfil dos usuários de adoçantes dietéticos entre a população usuária da $A B / S U S$, nas regiões do Brasil, segundo variáveis demográficas, socioeconômicas, estilo de vida e estado de saúde.

\section{MÉTODO}

Trata-se de estudo exploratório, descritivo, de corte transversal, realizado com dados da Pesquisa Nacional sobre Acesso, Utilização e Promoção do Uso Racional de Medicamentos (PNAUM), componente Serviços. A PNAUM foi instituída pelo Ministério da Saúde - Portaria do Ministério da Saúde (MS) $n^{\circ} 2.077$, de 17 de setembro de $2012^{23}$ - e teve dois componentes de abrangência nacional: um inquérito populacional ${ }^{24}$ e o componente serviços, um estudo transversal, exploratório, de natureza avaliativa, cuja produção de dados foi realizada entre 2014 e 2015. O método do componente serviço está descrito, minuciosamente, em Álvares et al. ${ }^{25}$.

A amostra da PNAUM foi composta por 600 municípios, representativos das regiões do Brasil, que constituem domínios do estudo, com um levantamento de informações numa amostra de serviços de AB/SUS, na qual se fez observação direta dos serviços farmacêuticos e entrevistas com uma amostra de usuários aí sorteados, entre outros entrevistados ${ }^{25}$. As entrevistas foram realizadas por entrevistadores capacitados, com questionário específico por categoria de entrevistado. A PNAUM foi aprovada pelo Comitê Nacional de Ética em Pesquisa do Conselho Nacional de Saúde (Parecer n 398.131/2013), esclarecendo aos entrevistados os objetivos da pesquisa e assinatura do Termo de Consentimento Livre e Esclarecido.

Este estudo utilizou o banco de dados da PNAUM, no que se refere aos usuários adultos acima de 18 anos que se encontravam nos serviços de $A B / S U S$ e que foram sorteados para serem entrevistados. No respectivo questionário constava a pergunta: você faz uso de algum adoçante na sua dieta? Os participantes que responderam afirmativamente foram selecionados do banco de dados, compondo a subamostra de usuários da AB/SUS do presente estudo.

Manteve-se a palavra adoçante, que foi utilizada no questionário da PNAUM, por ser a palavra comumente usada no Brasil em referência ao adoçante dietético, termo técnico do produto.

Para este trabalho, selecionou-se do banco de dados da PNAUM um conjunto de variáveis relativas a características socioeconômicas e demográficas dos usuários (região, sexo, faixa etária, escolaridade, estado civil e classe econômica segundo a Associação Brasileira de Empresas de Pesquisa - ABEP, utilizada pela PNAUM); estilo de vida (prática de exercício físico ou esporte, uso de fumo e dietas) e estado de saúde (problemas de saúde autorreferidos e autoavaliação de saúde).

Os dados foram processados com o programa Statistical Package for Social Science for Windows (SPSS), versão 22, módulo de análise para amostras complexas, utilizado pela PNAUM, com a finalidade de correção de eventuais vieses amostrais ${ }^{25}$. Para a análise de associação estatística aplicou-se o teste do Qui-quadrado, com nível de significância de $\mathrm{p}<0,05^{26}$.

\section{RESULTADOS}

Dos 8.803 usuários na AB/SUS entrevistados pela PNAUM, 21,0\% (1.802) declararam usar adoçantes dietéticos; suas características demográficas e socioeconômicas são apresentadas na Tabela 1.

O uso de adoçante dietético distribuiu-se pelas regiões observando-se diferenças estatísticas significantes, com maior proporção de uso na Sul e menor na Centro-Oeste. A proporção de uso por mulheres foi maior do que a de homens nas regiões e no Brasil. 0 uso foi maior nas faixas etárias mais elevadas; entre as mulheres na faixa etária 40-59 anos e entre os homens na faixa etária de 60 anos ou mais, com diferenças estatísticas significantes entre as regiões.

No que concerne à escolaridade, a proporção de usuários de adoçantes dietéticos foi maior entre as pessoas com nível de escolaridade fundamental e mais elevada no Centro-Oeste e menor no Sul. Nesta variável, não se observaram diferenças estatisticamente significantes entre as regiões.

No que se refere ao estado civil, a proporção de usuários de adoçantes dietéticos na AB/SUS foi maior entre os homens casados na Região Sul e entre as mulheres casadas no Sudeste, com diferenças estatísticas significantes entre as regiões.

Quanto à classe econômica codificada, houve um predomínio no uso de adoçante dietético entre as pessoas da classe $C$, mulheres e homens, com maior proporção de uso no Centro-Oeste e diferenças estatísticas significantes entre as regiões.

As características dos usuários de adoçantes dietéticos em relação ao estilo de vida e à dieta constam da Tabela 2. Cerca de um terço das mulheres e um pouco menos dos homens declararam ter praticado exercícios físicos ou esportes nos últimos três meses antes da entrevista. O maior percentual foi encontrado no Sul e o menor no Norte, em ambos os sexos, sem diferenças estatísticas significantes entre as regiões.

No que se refere ao tabagismo, $8,9 \%$ das mulheres e $11,7 \%$ dos homens usuários de adoçantes dietéticos declararam fumar atualmente; o maior percentual entre os homens foi encontrado no Sul $(16,3 \%)$ e, entre as mulheres, no Nordeste $(9,8 \%)$, contudo, as diferenças entre as regiões não foram estatisticamente significantes.

Quanto a dietas, 43,0\% das mulheres usuárias de adoçantes declararam fazer dieta para perder peso; esse percentual ultrapassou os $50,0 \%$ no Norte. Entre os homens, a proporção foi de $25,0 \%$ no Brasil e o uso mais elevado no Centro-Oeste $(47,0 \%)$, observando-se diferenças estatísticas significantes entre as regiões. 
Tabela 1. Características socioeconômicas e demográficas dos usuários de adoçantes dietéticos, na Atenção Básica/Sistema Único de Saúde, por região do Brasil. PNAUM, 2015 - Serviços $(n=1.802)$.

\begin{tabular}{|c|c|c|c|c|c|c|c|c|c|c|c|c|}
\hline \multirow{2}{*}{ Variáveis } & \multicolumn{2}{|c|}{ Norte } & \multicolumn{2}{|c|}{ Nordeste } & \multicolumn{2}{|c|}{ Centro-Oeste } & \multicolumn{2}{|c|}{ Sudeste } & \multicolumn{2}{|c|}{ Sul } & \multicolumn{2}{|c|}{ Brasil } \\
\hline & $\mathbf{n}$ & $\%$ & n & $\%$ & n & $\%$ & $\mathbf{n}$ & $\%$ & $\mathrm{n}$ & $\%$ & n & $\%$ \\
\hline \multicolumn{13}{|c|}{ Número $(\mathrm{n})$ de usuários de adoçantes dietéticos e percentual (\%) ponderado por região do Brasil } \\
\hline $\mathrm{N}^{\circ}$ de usuários & 289 & 18,7 & 397 & 23,6 & 200 & 13,2 & 430 & 23,5 & 486 & 24,1 & 1802 & 21,0 \\
\hline $\mathrm{F}$ & 229 & 78,4 & 316 & 76,4 & 155 & 77,1 & 342 & 78,1 & 376 & 77,0 & 1418 & 77,3 \\
\hline$M$ & 60 & 21,6 & 81 & 23,6 & 45 & 22,9 & 88 & 21,9 & 110 & 23,0 & 384 & 22,7 \\
\hline \multicolumn{13}{|c|}{ Características dos usuários de adoçantes dietéticos (\%) e intervalo de confiança (IC) } \\
\hline & $\%$ & IC95\% & $\%$ & IC95\% & $\%$ & IC95\% & $\%$ & IC95\% & $\%$ & IC95\% & $\%$ & IC95\% \\
\hline \multicolumn{13}{|l|}{ Sexo } \\
\hline $\mathrm{F}$ & 78,4 & $72,7-83,1$ & 76,4 & $70,5-81,4$ & 77,1 & $69,2-83,5$ & 78,1 & $72,9-82,6$ & 77,0 & $72,0-81,3$ & 77,3 & $74,5-79,9$ \\
\hline$M$ & 21,6 & $16,9-27,3$ & 23,6 & $18,6-29,5$ & 22,9 & $16,5-30,8$ & 21,9 & $17,4-27,1$ & 23,0 & $18,7-28,0$ & 22,7 & $20,1-25,5$ \\
\hline \multicolumn{13}{|l|}{ Faixa etária } \\
\hline \multicolumn{13}{|l|}{$\mathrm{F}$} \\
\hline $18-39$ & 38,7 & $32,0-45,7$ & 23,9 & $18,2-30,6$ & 26,4 & $18,6-35,9$ & 21,1 & $16,3-26,9$ & 22,3 & $17,5-28,0$ & 23,3 & $20,4-26,4$ \\
\hline $40-59$ & 39,2 & $32,5-46,3$ & 46,2 & $39,0-53,5$ & 42,4 & $33,2-52,2$ & 41,2 & $35,0-47,8$ & 42,4 & $36,4-48,7$ & 43,0 & $39,4-46,6$ \\
\hline 60 ou + & 22,1 & $16,8-28,5$ & 30,0 & $23,7-37,1$ & 31,2 & $22,9-40,9$ & 37,6 & $31,5-44,2$ & 35,2 & $29,5-41,4$ & 33,8 & $30,4-37,3$ \\
\hline \multicolumn{13}{|l|}{$M$} \\
\hline $18-39$ & 2,1 & $0,5-8,2$ & 12,4 & $6,2-23,5$ & 17,8 & $7,8-35,8$ & 7,5 & $3,3-16,0$ & 16,3 & $9,3-27,0$ & 11,4 & $7,9-16,2$ \\
\hline $40-59$ & 47,9 & $34,8-61,4$ & 35,9 & $24,4-49,4$ & 30,5 & $16,8-48,8$ & 47,9 & $35,7-60,3$ & 42,0 & $31,2-53,6$ & 42,0 & $35,4-48,8$ \\
\hline 60 ou + & 49,9 & $36,6-63,2$ & 51,6 & $38,6-64,5$ & 51,7 & $34,4-68,6$ & 44,7 & $32,8-57,2$ & 41,7 & $31,1-53,2$ & 46,6 & $39,9-53,4$ \\
\hline \multicolumn{13}{|c|}{ Escolaridade codificada } \\
\hline Analfabeto & & & & & & & & & & & & \\
\hline $\mathrm{F}$ & 5,9 & $3,3-10,3$ & 17,2 & $12,3-23,4$ & 7,4 & $3,6-14,5$ & 6,4 & $3,9-10,2$ & 13,2 & $9,5-18,2$ & 11,4 & $9,3-13,9$ \\
\hline M & 14,8 & $7,3-27,6$ & 16,8 & $8,9-29,2$ & 7,7 & $1,9-25,9$ & 5,4 & $1,8-15,4$ & 20,1 & $12,3-31,1$ & 13,3 & $9,3-18,6$ \\
\hline Fundamenta & & & & & & & & & & & & \\
\hline $\mathrm{F}$ & 50,2 & $43,2-57,2$ & 52,5 & $45,2-59,6$ & 59,7 & $49,9-68,8$ & 58,8 & $52,3-65,0$ & 48,0 & $41,8-54,2$ & 53,8 & $50,1-57,3$ \\
\hline M & 65,6 & $52,3-76,8$ & 63,7 & $50,4-75,2$ & 71,8 & $53,6-84,9$ & 60,8 & $48,3-72,0$ & 53,5 & $42,0-64,6$ & 60,4 & $53,7-66,8$ \\
\hline Médio & & & & & & & & & & & & \\
\hline $\mathrm{F}$ & 33,5 & $27,2-40,4$ & 25,3 & $19,6-32,0$ & 25,3 & $17,8-34,5$ & 30,2 & $24,6-36,4$ & 28,4 & $23,0-34,4$ & 28,2 & $25,1-31,6$ \\
\hline M & 18,6 & $11,0-29,7$ & 18,1 & $10,1-30,3$ & 20,0 & $9,4-37,4$ & 25,9 & $16,7-38,0$ & 19,3 & $11,9-29,7$ & 21,2 & $18,2-27,2$ \\
\hline Superior & & & & & & & & & & & & \\
\hline $\mathrm{F}$ & 10,4 & $6,8-15,5$ & 5,1 & $2,7-9,3$ & 7,6 & $3,8-14,6$ & 4,7 & $2,7-8,1$ & 10,5 & $7,2-14,9$ & 6,6 & $5,1-8,5$ \\
\hline M & 1,1 & $0,1-7,3$ & 1,4 & $0,3-7,7$ & 0,5 & $0,1-3,8$ & 7,9 & $3,6-16,6$ & 7,1 & $3,0-15,8$ & 5,1 & $2,9-8,7$ \\
\hline Estado civil & & & & & & & & & & & & \\
\hline Solteiro & & & & & & & & & & & & \\
\hline $\mathrm{F}$ & 20,3 & $15,3-26,4$ & 19,8 & $14,8-26,0$ & 17,9 & $11,5-26,8$ & 13,5 & $9,8-18,3$ & 14,0 & $10,3-18,9$ & 16,0 & $13,6-18,8$ \\
\hline M & 18,0 & $9,8-30,7$ & 10,8 & $5,0-21,8$ & 28,5 & $15,0-47,4$ & 5,5 & $2,2-12,9$ & 7,9 & $3,7-16,3$ & 9,1 & $6,2-13,4$ \\
\hline Casado & & & & & & & & & & & & \\
\hline $\mathrm{F}$ & 51,8 & $44,7-58,7$ & 47,6 & $40,5-54,9$ & 54,3 & $44,5-63,7$ & 59,2 & $52,7-65,4$ & 53,4 & $47,1-59,5$ & 53,7 & $50,1-57,3$ \\
\hline M & 44,7 & $31,8-58,4$ & 64,9 & $51,6-76,2$ & 59,6 & $41,4-75,5$ & 61,8 & $49,2-73,1$ & 69,3 & $57,9-78,8$ & 63,9 & $57,2-70,1$ \\
\hline União estáve & & & & & & & & & & & & \\
\hline $\mathrm{F}$ & 19,0 & $14,0-25,3$ & 14,8 & $10,3-20,7$ & 12,7 & $7,4-21,1$ & 9,6 & $6,4-14,3$ & 7,4 & $4,7-11,5$ & 11,2 & $9,1-13,7$ \\
\hline M & 12,4 & $5,8-24,5$ & 10,8 & $5,0-21,9$ & 3,8 & $0,5-22,7$ & 13,5 & $6,9-24,6$ & 5,8 & $2,3-13,7$ & 10,3 & $6,8-15,3$ \\
\hline Divorciado / & parado & & & & & & & & & & & \\
\hline $\mathrm{F}$ & 3,2 & $1,6-6,0$ & 5,1 & $2,8-9,2$ & 7,6 & $4,0-14,0$ & 7,4 & $4,7-11,6$ & 10,5 & $7,3-14,8$ & 7,3 & $5,7-9,3$ \\
\hline$M$ & 12,4 & $6,0-24,0$ & 9,4 & $4,1-20,1$ & 8,0 & $2,4-23,8$ & 17,4 & $9,7-29,2$ & 11,4 & $5,8-21,4$ & 12,8 & $8,8-18,1$ \\
\hline viúvo & & & & & & & & & & & & \\
\hline $\mathrm{F}$ & 5,7 & $3,3-9,9$ & 12,6 & $8,5-18,5$ & 7,5 & $3,9-14,0$ & 10,2 & $7,0-14,8$ & 14,7 & $10,8-19,6$ & 11,8 & $9,6-14,3$ \\
\hline M & 12,4 & $5,8-24,7$ & 4,1 & $1,0-14,9$ & - & - & 1,8 & $0,3-11,7$ & 5,6 & $2,1-13,6$ & 3,9 & $2,0-7,5$ \\
\hline Classe econômi & codific & & & & & & & & & & & \\
\hline $\mathrm{F}$ & & & & & & & & & & & & \\
\hline$A$ e $B$ & 9,6 & $6,2-14,4$ & 5,8 & $3,3-10,0$ & 10,9 & $6,3-18,1$ & 16,1 & $12,0-21,3$ & 30,1 & $24,7-36,2$ & 16,0 & $13,7-18,7$ \\
\hline$C$ & 48,3 & $41,3-55,3$ & 38,7 & $32,0-45,9$ & 67,3 & $57,7-75,7$ & 51,8 & $45,2-58,2$ & 60,4 & $54,1-66,3$ & 50,3 & $46,7-53,9$ \\
\hline$D$ e $E$ & 42,2 & $35,4-49,3$ & 55,5 & $48,2-62,5$ & 21,8 & $14,7-31,0$ & 32,1 & $26,2-38,7$ & 9,5 & $6,4-13,9$ & 33,7 & $30,2-37,3$ \\
\hline$M$ & & & & & & & & & & & & \\
\hline$A e B$ & 5,9 & $2,2-14,7$ & 9,1 & $4,0-19,4$ & 18,1 & $8,0-35,9$ & 22,8 & $14,2-34,4$ & 34,5 & $24,4-46,1$ & 20,5 & $15,7-26,3$ \\
\hline$C$ & 51,1 & $37,7-64,3$ & 44,0 & $31,6-57,2$ & 60,0 & $41,9-75,7$ & 49,9 & $37,6-62,2$ & 58,7 & $47,1-69,4$ & 50,7 & $43,9-57,4$ \\
\hline$D$ e $E$ & 43,0 & $30,2-56,9$ & 46,9 & $34,1-60,0$ & 21,9 & $10,5-40,1$ & 27,3 & $17,5-40,1$ & 6,9 & $2,8-15,6$ & 28,8 & $22,9-35,6$ \\
\hline
\end{tabular}

Fonte: PNAUM - Serviços ${ }^{23}$

F: Feminino; M: Masculino; p-valor $<0,05$. 
Mais de $87,0 \%$ das mulheres do estudo declararam evitar o consumo de sal e a Região Sudeste apresentou proporção maior. Entre os homens, o percentual encontrado foi de $82,6 \%$ no país; entre as regiões, o Norte alcançou o maior percentual e o menor foi no Sul.

Mais de $88,0 \%$ das usuárias de adoçantes dietéticos no Brasil declararam fazer dieta para reduzir o consumo de gorduras, o maior percentual foi no Nordeste; entre os homens, foi $78,0 \%$ e o maior percentual no Norte. Observou-se variação entre as regiões, em ambos os sexos, com proporção maior entre as mulheres. As diferenças estatísticas entre as regiões foram significantes.

No referente à dieta para reduzir o consumo de açúcar, no país, a proporção de mulheres foi $90,0 \%$ e a região com o maior percentual foi a Nordeste. Aproximadamente $85,0 \%$ dos homens declararam fazer tal dieta, no Norte, verificou-se o maior percentual. Contudo, não houve diferenças estatísticas significantes entre as regiões.

A Tabela 3 apresenta algumas características das condições de saúde dos usuários de adoçantes na AB/SUS. Mais de $59,0 \%$ das mulheres e cerca de $63,0 \%$ dos homens referiram ter hipertensão diagnosticada por profissional de saúde. As maiores proporções de hipertensão referida foram de mulheres no Sudeste e de homens no Nordeste. Sem diferenças estatísticas significantes entre as regiões.

Os percentuais dos que afirmaram ter dislipidemia foram bem próximos entre mulheres $(41,8 \%)$ e homens $(42,5 \%)$. Nas Regiões Nordeste e Centro-Oeste, os percentuais foram mais elevados entre as mulheres e, no Sudeste, entre os homens. Verificaram-se diferenças estatísticas significantes entre as regiões.
Mais de 28,0\% das mulheres usuárias de adoçantes dietéticos afirmaram ser portadoras de diabetes e mais de $10,0 \%$ dos homens. Encontraram-se percentuais mais elevados no Centro-Oeste em ambos os sexos e diferenças estatisticamente significantes entre as regiões do país.

A depressão foi um problema de saúde referido por $25,8 \%$ das mulheres e por $17,6 \%$ dos homens. Em todas as regiões, os percentuais de mulheres que declararam ter esta doença foram sempre mais altos que os dos homens e maiores na Região Sul para ambos os sexos. Verificaram-se diferenças estatísticas significantes entre as regiões do país.

Quanto à autoavaliação de saúde, predominou a declaração de saúde boa, em percentuais muito próximos entre mulheres $(42,6 \%)$ e homens $(41,5 \%)$; seguiu-se saúde nem boa nem ruim, em percentuais igualmente próximos. 0 percentual de declaração de saúde ruim foi maior entre os homens no país e nas regiões, exceto na Centro-oeste, tendo o Nordeste revelado os maiores percentuais para ambos os sexos. Não se observaram diferenças estatísticas significantes entre as regiões do Brasil.

Considerando que o uso de adoçantes dietéticos pode estar associado a ter diabetes, buscou-se comparar os dois grupos: usuários de adoçantes que declararam ter diabetes diagnosticado por profissional de saúde e os que afirmaram não ter a doença (Figura). $\mathrm{Na} A B / \mathrm{SUS}, 38,9 \%$ dos usuários de adoçantes dietéticos afirmaram ter diabetes, os demais $(61,1 \%)$ referiram não ter a doença.

Conforme a Figura, mulheres com diabetes diagnosticada por profissional de saúde ocuparam maiores percentuais do que

Tabela 2. Características dos usuários de adoçantes dietéticos, na Atenção Básica/Sistema Único de Saúde, por região do Brasil, quanto a estilo de vida e dietas. PNAUM, $2015(\mathrm{n}=1.802)$.

\begin{tabular}{|c|c|c|c|c|c|c|c|c|c|c|c|c|}
\hline \multirow{2}{*}{ Variáveis } & \multicolumn{2}{|c|}{ Norte } & \multicolumn{2}{|c|}{ Nordeste } & \multicolumn{2}{|c|}{ Centro-Oeste } & \multicolumn{2}{|c|}{ Sudeste } & \multicolumn{2}{|c|}{ Sul } & \multicolumn{2}{|c|}{ Brasil } \\
\hline & $\%$ & IC95\% & $\%$ & IC95\% & $\%$ & IC95\% & $\%$ & IC95\% & $\%$ & IC95\% & $\%$ & IC95\% \\
\hline \multicolumn{13}{|c|}{ Nos últimos 3 meses, praticou exercício físico ou esporte } \\
\hline $\mathrm{F}$ & 25,4 & $19,8-31,9$ & 27,0 & $21,1-33,8$ & 42,3 & $33,1-52,1$ & 30,2 & $24,6-36,4$ & 44,4 & $38,3-50,7$ & 33,0 & $29,7-36,4$ \\
\hline M & 15,6 & $8,4-27,1$ & 20,3 & $11,9-32,5$ & 23,2 & $11,7-40,8$ & 30,4 & $20,2-42,9$ & 48,0 & $36,8-59,4$ & 30,8 & $25,0-37,3$ \\
\hline \multicolumn{13}{|c|}{ Fuma atualmente } \\
\hline $\mathrm{F}$ & 2,6 & $1,2-5,8$ & 9,6 & $6,1-14,9$ & 8,8 & $4,5-16,4$ & 9,1 & $6,0-13,7$ & 8,7 & $5,9-12,8$ & 8,9 & $7,0-11,2$ \\
\hline$M$ & 9,2 & $3,5-22,1$ & 11,0 & $4,9-22,7$ & 3,6 & $0,7-17,6$ & 10,0 & $4,7-20,3$ & 16,3 & $9,5-26,5$ & 11,7 & $8,0-16,8$ \\
\hline \multicolumn{13}{|c|}{ Faz dieta para perder peso } \\
\hline $\mathrm{F}$ & 51,2 & $44,1-58,1$ & 34,8 & $28,3-42,0$ & 45,4 & $36,0-55,3$ & 48,1 & $41,7-54,7$ & 43,6 & $37,5-49,8$ & 43,0 & $39,4-46,6$ \\
\hline M & 32,7 & $21,5-46,2$ & 12,2 & $6,0-23,3$ & 47,0 & $30,3-64,5$ & 32,4 & $21,8-45,2$ & 26,7 & $18,0-37,8$ & 25,0 & $19,7-31,2$ \\
\hline \multicolumn{13}{|c|}{ Evita consumo de sal } \\
\hline $\mathrm{F}$ & 88,8 & $83,5-92,5$ & 83,7 & $77,8-88,4$ & 86,0 & $77,6-91,6$ & 91,7 & $87,5-94,6$ & 86,8 & $82,1-90,4$ & 87,7 & $85,2-89,9$ \\
\hline M & 81,0 & $68,1-89,6$ & 86,5 & $74,8-93,3$ & 83,7 & $66,0-93,2$ & 81,7 & $70,2-89,5$ & 78,9 & $68,0-86,8$ & 82,6 & $76,9-87,1$ \\
\hline \multicolumn{13}{|c|}{ Faz dieta para reduzir o consumo da gordura } \\
\hline $\mathrm{F}$ & 89,7 & $84,6-93,3$ & 90,8 & $86,0-94,1$ & 85,1 & $76,6-90,9$ & 88,0 & $83,0-91,6$ & 86,3 & $81,5-90,0$ & 88,4 & $85,9-90,5$ \\
\hline$M$ & 85,8 & $73,9-92,8$ & 79,1 & $66,2-88,0$ & 68,7 & $50,1-82,7$ & 78,1 & $66,1-86,8$ & 76,6 & $65,5-84,9$ & 78,1 & $71,9-83,2$ \\
\hline \multicolumn{13}{|c|}{ Faz dieta para reduzir o açúcar } \\
\hline $\mathrm{F}$ & 90,1 & $85,2-93,5$ & 92,8 & $88,3-95,6$ & 82,3 & $73,4-88,7$ & 90,0 & $85,2-93,3$ & 87,8 & $83,2-91,3$ & 90,0 & $87,7-91,9$ \\
\hline M & 95,5 & $85,9-98,7$ & 88,5 & $77,3-94,6$ & 84,3 & $66,4-93,6$ & 86,1 & $74,9-92,8$ & 76,2 & $65,0-84,7$ & 84,7 & $79,2-88,9$ \\
\hline
\end{tabular}

Fonte: PNAUM - Serviços ${ }^{23}$

F: Feminino; M: Masculino; p-valor $<0,05$. 
Paz BMS \& Costa EA Uso de adoçantes dietéticos por usuários da Atenção Básica no SUS, Brasil

Tabela 3. Condições de saúde referidas pelos usuários de adoçantes dietéticos, na Atenção Básica/Sistema Único de Saúde, por região do Brasil. PNAUM - $2015(n=1.802)$

\begin{tabular}{|c|c|c|c|c|c|c|c|c|c|c|c|c|}
\hline \multirow{2}{*}{ Variáveis } & \multicolumn{2}{|c|}{ Norte } & \multicolumn{2}{|c|}{ Nordeste } & \multicolumn{2}{|c|}{ Centro-Oeste } & \multicolumn{2}{|c|}{ Sudeste } & \multicolumn{2}{|c|}{ Sul } & \multicolumn{2}{|c|}{ Brasil } \\
\hline & $\%$ & IC95\% & $\%$ & IC95\% & $\%$ & IC95\% & $\%$ & IC95\% & $\%$ & IC95\% & $\%$ & IC95\% \\
\hline \multicolumn{13}{|c|}{ Hipertensão } \\
\hline $\mathrm{F}$ & 39,0 & $32,4-46,1$ & 57,7 & $50,5-64,7$ & 53,3 & $43,5-62,8$ & 65,0 & $58,6-70,9$ & 57,7 & $51,4-63,7$ & 59,3 & $55,7-62,8$ \\
\hline M & 45,7 & $32,8-59,2$ & 70,5 & $57,3-81,0$ & 65,6 & $47,2-80,3$ & 58,9 & $46,4-70,4$ & 60,5 & $49,0-71,1$ & 62,7 & $56,0-68,9$ \\
\hline \multicolumn{13}{|c|}{ Dislipidemia (colesterol/triglicérides altos) } \\
\hline $\mathrm{F}$ & 39,4 & $32,8-46,5$ & 46,4 & $39,3-53,6$ & 46,0 & $36,5-55,8$ & 42,0 & $35,7-48,5$ & 35,8 & $30,0-42,0$ & 41,8 & $38,2-45,4$ \\
\hline M & 25,3 & $15,8-37,9$ & 40,6 & $28,4-54,1$ & 32,3 & $18,5-50,2$ & 48,2 & $36,1-60,6$ & 41,5 & $30,8-53,0$ & 42,5 & $35,9-49,4$ \\
\hline \multicolumn{13}{|c|}{ Diabetes mellitus } \\
\hline $\mathrm{F}$ & 21,0 & $16,4-26,6$ & 28,7 & $23,3-34,7$ & 36,6 & $28,8-45,2$ & 32,0 & $26,9-37,6$ & 22,8 & $18,5-27,7$ & 28,3 & $25,5-31,3$ \\
\hline M & 12,5 & $8,8-17,4$ & 10,5 & $7,1-15,1$ & 13,5 & $8,6-20,5$ & 10,7 & $7,6-14,8$ & 9,7 & $6,9-13,4$ & 10,6 & $8,8-12,7$ \\
\hline \multicolumn{13}{|l|}{ Depressão } \\
\hline $\mathrm{F}$ & 9,8 & $6,5-14,5$ & 22,1 & $16,7-28,7$ & 19,0 & $12,5-27,7$ & 23,5 & $18,4-29,4$ & 37,4 & $31,6-43,7$ & 25,8 & $22,7-29,1$ \\
\hline M & 9,0 & $3,8-19,7$ & 14,8 & $7,9-26,3$ & 13,2 & $4,9-30,7$ & 17,3 & $9,7-29,0$ & 23,6 & $15,1-34,9$ & 17,6 & $13,1-23,4$ \\
\hline \multicolumn{13}{|c|}{ Auto avaliação de saúde } \\
\hline \multicolumn{13}{|c|}{ Muito boa } \\
\hline $\mathrm{F}$ & 5,5 & $3,2-9,5$ & 6,0 & $3,3-10,5$ & 11,9 & $6,7-20,2$ & 10,1 & $6,7-14,9$ & 7,5 & $4,8-11,4$ & 8,0 & $6,2-10,3$ \\
\hline M & - & - & 4,1 & $1,0-14,9$ & 3,6 & $0,7-17,6$ & 9,4 & $4,4-19,0$ & 5,3 & $2,0-13,5$ & 6,1 & $3,5-10,3$ \\
\hline \multicolumn{13}{|l|}{ Boa } \\
\hline $\mathrm{F}$ & 51,2 & $44,2-58,2$ & 36,8 & $30,1-44,0$ & 41,8 & $32,6-51,7$ & 42,7 & $36,4-49,3$ & 48,1 & $41,9-54,3$ & 42,6 & $39,1-46,2$ \\
\hline M & 48,9 & $35,7-62,3$ & 25,9 & $16,2-38,6$ & 39,9 & $24,0-58,2$ & 50,2 & $38,0-62,5$ & 48,1 & $36,9-59,4$ & 41,5 & $35,5-48,3$ \\
\hline \multicolumn{13}{|c|}{ Nem ruim nem boa } \\
\hline $\mathrm{F}$ & 35,3 & $28,8-42,3$ & 44,2 & $37,2-51,4$ & 36,7 & $27,9-46,4$ & 39,0 & $32,9-45,5$ & 35,2 & $29,5-41,4$ & 39,4 & $35,9-43,0$ \\
\hline M & 42,1 & $29,6-55,7$ & 57,0 & $43,8-69,3$ & 51,8 & $34,4-68,7$ & 30,3 & $20,1-42,8$ & 30,5 & $21,0-42,0$ & 40,1 & $33,6-47,0$ \\
\hline \multicolumn{13}{|l|}{ Ruim } \\
\hline $\mathrm{F}$ & 6,9 & $4,2-11,1$ & 11,7 & $7,7-17,3$ & 6,3 & $2,9-13,0$ & 6,4 & $3,9-10,3$ & 7,2 & $4,5-11,3$ & 8,2 & $6,4-10,5$ \\
\hline M & 9,0 & $3,6-20,7$ & 12,8 & $6,3-24,5$ & 4,7 & $1,2-16,7$ & 8,0 & $3,3-18,0$ & 11,3 & $5,6-21,2$ & 10,3 & $6,8-15,3$ \\
\hline \multicolumn{13}{|c|}{ Muito ruim } \\
\hline $\mathrm{F}$ & 1,1 & $0,3-4,0$ & 1,4 & $0,5-4,1$ & 3,4 & $1,1-9,5$ & 1,3 & $0,5-3,7$ & 1,6 & $0,6-4,2$ & 1,5 & $0,8-2,5$ \\
\hline$M$ & - & - & 0,2 & $0,0-1,4$ & - & - & 2,1 & $0,4-10,8$ & 4,9 & $1,7-13,4$ & 2,0 & $0,8-4,9$ \\
\hline
\end{tabular}

Fonte: PNAUM - Serviços ${ }^{23}$.

F: Feminino; M: Masculino; p-valor $<0,05$.

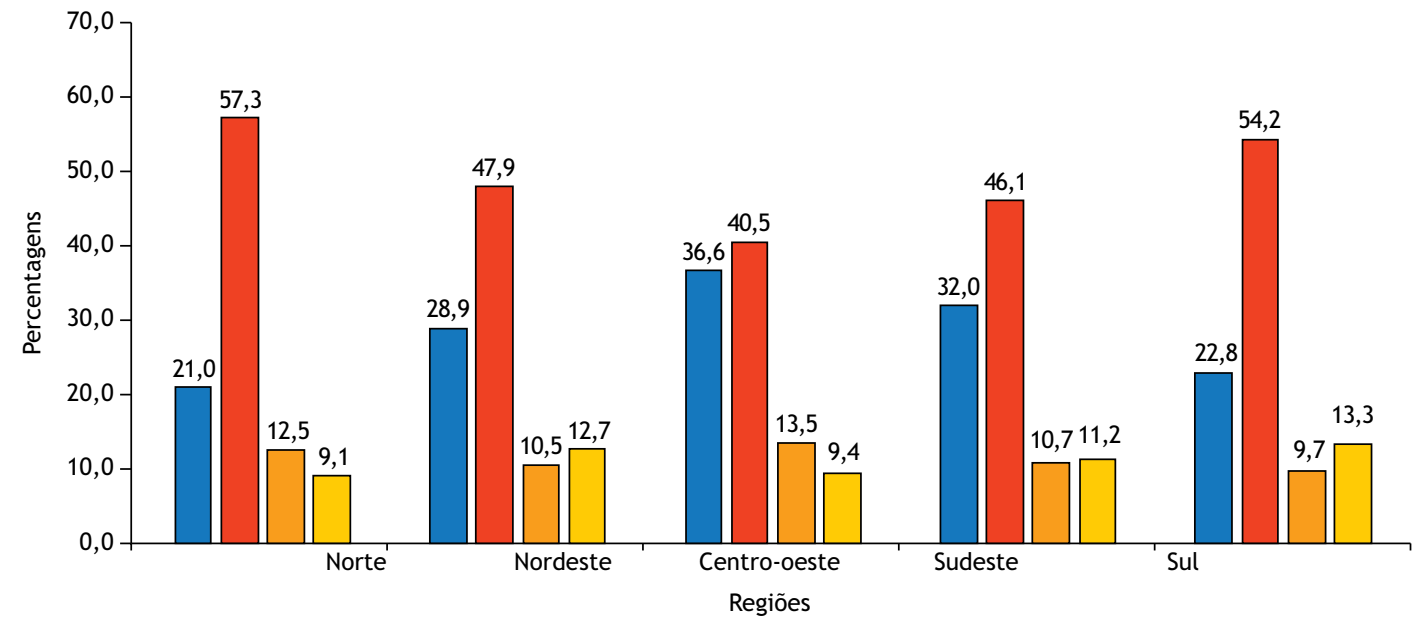

Fonte: PNAUM - Serviços ${ }^{23}$

$\square$ Mulheres com diabetes $\square$ Mulheres sem diabetes $\square$ Homens com diabetes $\square$ Homens sem diabetes

Figura. Uso de adoçantes dietéticos por mulheres e homens com e sem diabetes, em percentagem, na Atenção Básica/Sistema Único de Saúde, por região do Brasil. PNAUM - Serviços $(n=1.802)$. 
os homens em todas as regiões, nesta ordem: Centro-Oeste, Sudeste, Nordeste, Sul e Norte. Todavia, em todas as regiões, verificaram-se percentuais mais elevados de usuárias de adoçantes dietéticos autodeclaradas não diabéticas. Entre os homens usuários de adoçantes que declaram ter diabetes, o maior percentual também foi no Centro-Oeste, seguido do Norte, Sudeste e Nordeste com taxas semelhantes $(10,7 \%$ e $10,5 \%$ respectivamente) e ligeiramente menor no Sul.

\section{DISCUSSÃO}

As principais características dos usuários da AB/SUS que declararam usar adoçantes dietéticos revelaram predomínio de mulheres, maior prevalência nas faixas etárias mais elevadas, entre os que declararam escolaridade fundamental, ser casado e pertencer à classe econômica C. Observou-se distribuição desigual no uso desses produtos entre as regiões, com maior proporção no Sul e menor no Centro-Oeste.

Algumas variáveis pesquisadas para indicar estilo de vida e hábitos mostraram maior proporção de prática de exercício físico entre os usuários de adoçantes dietéticos (33,0\% mulheres e $30,8 \%$ homens) comparada aos usuários da $A B / S U S$ em geral $\left(25,3 \%\right.$ mulheres e $28,5 \%$ homens $\left.^{27}\right)$. A proporção dos que se declararam fumantes $(11,7 \%$ homens e $8,9 \%$ mulheres) foi menor do que a encontrada no conjunto de usuários da AB/SUS ${ }^{27}$ ( $11,3 \%$ mulheres e $19,8 \%$ homens) e mais elevada do que no Vigitel/2016, no sexo feminino ${ }^{28}$. Neste estudo, a maior proporção entre os homens foi no Sul e entre as mulheres, no Nordeste. $\mathrm{Na}$ $A B / S U S$ em geral ${ }^{27}$, as maiores proporções de homens e mulheres fumantes foi no Sul, tal como em dietas de redução de sal, gorduras e açúcar.

Sobre as condições de saúde, os homens apresentaram maiores proporções de referência a diagnóstico de hipertensão e dislipidemia, enquanto as mulheres, de diabetes e de depressão. A pesquisa Vigitel/2016 28 encontrou, nas capitais e no Distrito Federal, maior frequência de hipertensão em mulheres (27,5\% versus $23,6 \%$ homens). Em ambos os sexos, a frequência aumentou com a idade e entre aqueles com menor nível de escolaridade ( 0 a 8 anos de estudo). No caso da diabetes, tal como neste estudo, a maior frequência encontrada pelo Vigitel foi entre mulheres, $9,9 \%$, enquanto entre os homens foi $7,8 \%$.

Chama a atenção que a maior parte dos usuários de adoçantes avaliou sua saúde como boa e nem ruim nem boa, seguindo-se a saúde ruim. No estudo de Guibu et al. ${ }^{27}$, o conjunto dos usuários da $A B / S U S$ avaliou sua saúde como muito boa, boa ou nem ruim nem boa.

Constatou-se que mais de $54,0 \%$ dos usuários de adoçantes dietéticos não receberam prescrição para o uso. Entre os que receberam, em mais de $76,0 \%$ dos casos o prescritor foi o médico. Sinaliza-se a importância de cuidado no uso de adoçantes, que são produtos com informações complexas e fórmulas associadas e ainda poucos estudos científicos indicando o consumo adequado e a prática segura para a prescrição. 0 uso requer orientações específicas, mas os rótulos ainda não apresentam informações suficientes para suprir essa necessidade ${ }^{29}$. Isto pode indicar que muitas pessoas os usam sem os devidos esclarecimentos.

Parece ser elevada a prevalência de $21,0 \%$ de uso de adoçantes dietéticos encontrada neste estudo, que é um pouco maior do que a prevalência de $19 \%$ na população de Pelotas/RS, conforme Zanini $^{30}$. Na população brasileira, Monteiro et al. ${ }^{20}$ estimaram o uso de adoçantes artificiais em 7,6\% e o uso concomitante com açúcar em 5,1\%.

Esses achados denotam o forte crescimento da comercialização e consumo de adoçantes e produtos dietéticos nos últimos anos ${ }^{5}$, especialmente na zona urbana $(8,5 \%)$ e nas Regiões Sudeste e Sul $(9,5 \%)$, mas o açúcar $(85,7 \%)$ ainda é preferido pelos brasileiros ${ }^{20}$. Como motivações para o uso de adoçantes dietéticos, citam-se a dificuldade em manter o peso corporal, a economia de calorias e o desejo de evitar engordar ${ }^{22}$. 0 presente trabalho é o primeiro estudo nacional sobre o tema na população usuária da $A B / S U S$.

Os maiores percentuais de uso de adoçantes nas faixas etárias mais elevadas, mulheres de 40-59 anos e homens acima de 60 anos aproximam-se aos de Zanini et al. ${ }^{21}$, que estimaram o uso em 3,7 vezes maior em idosos comparados à faixa-etária de 20-29 anos. Outros estudos também encontraram maior uso entre pessoas de idades mais avançadas ${ }^{20,22}$.

Estudos publicados no Brasil e em outros países apresentaram resultados de pesquisas que mostraram o uso de adoçantes dietéticos por gestantes e indiretamente até por lactentes e pela população intrauterina, visto que tem sido detectada a presença dessas substâncias no leite materno ${ }^{31,32,33,34}$. Esses achados são relevantes para contribuir com as reflexões sobre riscos e regulação sanitária desses produtos, especialmente pelo possível uso indiscriminado e em fases delicadas da vida. Este estudo não conferiu destaque a gestantes, eventualmente entrevistadas.

Rother et al. ${ }^{31}$ observaram que lactantes que amamentam exclusivamente e que consomem bebidas contendo sucralose e acessulfame $\mathrm{K}$ apresentavam tais adoçantes no leite materno. Concluíram que os bebês amamentados por mães que fazem uso desses adoçantes ingerem, por conseguinte, os referidos produtos. As autoras alertaram para a possibilidade de resultados subestimados no referente ao consumo infantil, visto que o uso materno de produtos contendo adoçantes dietéticos ocorre em ocasiões diversas e ao longo de vários dias; alertaram também para possíveis potenciais implicações metabólicas para as crianças expostas.

Esse alerta serve tanto à sociedade em geral como, em especial, aos estudiosos e profissionais de saúde, incluindo os da vigilância sanitária, posto que, de acordo com Araújo et al. ${ }^{33}$, a nutrição é crucial na programação intrauterina para o risco de estabelecimento de doenças futuras. Além disso, estes autores referiram que estudos com animais sob consumo de adoçantes dietéticos (em particular o aspartame) por longo prazo, durante o período perigestacional, obtiveram resultados positivos para a indução de fenótipo adverso predisponente ao desenvolvimento 
de doenças metabólicas em fases posteriores da vida, embora a extrapolação para humanos exija estudos criteriosos.

No que se refere à escolaridade, neste estudo a maior proporção de uso de adoçantes ocorreu entre os que declararam escolaridade fundamental, o que divergiu de outros estudos que encontraram as maiores proporções entre os usuários com 12 ou mais e 16 ou mais anos de estudo ${ }^{21,22}$. Assinalem-se as distintas populações desses estudos: a primeira, usuários da AB/SUS, entre os quais predomina a escolaridade fundamental; a segunda, moradores da zona urbana da cidade de Pelotas ${ }^{21}$, e a última, funcionários de universidades públicas do estado de São Paulo ${ }^{22}$.

Neste estudo, a maioria dos usuários de adoçantes de ambos os sexos era casada. Geraldo e Silva ${ }^{22}$ encontraram cerca de $61 \%$ de casados entre os entrevistados que referiram consumir adoçantes. Contudo, o oposto foi observado no trabalho de Zanini et al. ${ }^{21}$, a maioria dos usuários de adoçantes não era casada.

Os resultados quanto à classe econômica também divergem de outros achados. No presente estudo, a maioria dos usuários de adoçantes dietéticos no Brasil pertencia à classe $C$ da ABEP, em ambos os sexos. Zanini et al. ${ }^{21}$ encontraram maior proporção de usuários desses adoçantes nas classes econômicas mais altas. Monteiro et al. ${ }^{20}$ observaram que o uso exclusivo de açúcar para adoçar alimentos decai à medida que a renda per capita aumenta, inclusive com uso menos frequente do açúcar nas Regiões Sul e Sudeste, em comparação com as demais. Precisa-se atentar que o estudo de Zanini et al. ${ }^{21}$ foi realizado na Região Sul do Brasil, reconhecida por melhores indicadores socioeconômicos, ao passo que a amostra deste estudo foi constituída por usuários da $A B$ /SUS e que a classe econômica $C$ abrange $55 \%$ da população usuária da AB/SUS ${ }^{27}$.

No tocante a algumas características referentes ao estilo de vida e dieta, constatou-se que a proporção dos que declararam ter praticado exercício físico ou esporte nos últimos três meses, mulheres $(33,0 \%)$ e homens $(30,8 \%)$, foi superior à encontrada entre os usuários da $A B / S U S$ em geral, dos quais as mulheres eram $25,3 \%$ e os homens $28,5 \%{ }^{27}$. No estudo de Geraldo e Silva ${ }^{22}$, os indivíduos que realizavam exercício físico duas a três vezes por semana eram os que mais consumiam adoçantes, mas as autoras ressaltaram que o consumo de adoçantes não é determinante para a prática de exercícios físicos, uma vez que nem todos consumidores foram considerados ativos.

A relação entre o uso de adoçantes ou outros produtos dietéticos e a boa saúde requer investigações. Pessoas associam o uso de produtos dietéticos/light à saudabilidade ${ }^{35}$, porém estudos identificaram referências de pessoas que relacionam sintomas físicos desagradáveis ao uso de adoçantes ${ }^{22,36}$. Ademais, Sylvetsky et al. ${ }^{34}$ compreenderam que pais de crianças em geral não percebem os adoçantes dietéticos como seguros para seus filhos e frequentemente não reconhecem que alimentos e bebidas comuns contenham adoçantes em sua composição. Diante disso, esses autores apoiaram a otimização da rotulagem e a implementação de abordagens que ampliem o conhecimento dos pais sobre a composição de alimentos e bebidas. Um rótulo seguro deve proporcionar bom entendimento sobre um produto, predispondo o consumidor à escolha consciente durante a compra de um alimento, o que exige da vigilância sanitária maior atenção no que se refere aos rótulos e à comunicação com a sociedade, com a finalidade de melhor orientá-la.

No presente trabalho, as proporções de usuários de adoçantes dietéticos declarantes de dieta para perder peso $(43,0 \%$ mulheres e $25,0 \%$ homens), redução do consumo de sal $(87,7 \%$ mulheres e $82,6 \%$ homens), de gordura ( $88,4 \%$ mulheres e $82,6 \%$ homens) e de açúcar ( $90,0 \%$ mulheres e $84,7 \%$ homens) foram bem mais elevadas que as encontradas no conjunto dos usuários da $A B$ / $\mathrm{SUS}^{27} \mathrm{e}$ as mulheres representaram percentagens sempre maiores que os homens em todas as dietas inquiridas. Até o momento não foram encontrados estudos nacionais de base populacional sobre os usuários de adoçantes dietéticos que abrangessem dietas específicas isoladamente, como nesta pesquisa, exceto no que se refere às dietas para perda de peso.

Pesquisadores ${ }^{37}$ referiram que, até o momento, não encontraram suporte consistente para afirmar os benefícios no uso de adoçantes não nutritivos para controle de peso e ainda que dados observacionais sugerem uma possível associação entre o uso rotineiro destes adoçantes e seus derivados e o aumento do risco cardiometabólico e do índice de massa corporal (IMC).

Um estudo em Pelotas encontrou associação direta e significativa entre o estado nutricional e o uso de adoçantes dietéticos, e o excesso de peso constituiu a segunda morbidade mais frequente ${ }^{21}$. Em estudo realizado em São Paulo, a maioria dos entrevistados informou utilizar adoçantes dietéticos para a manutenção do peso ${ }^{22}$. Porém, há controvérsias quanto ao uso de adoçantes para perder peso, posto que pesquisas referiram relatos de aumento no IMC entre os que utilizam tais produtos ${ }^{34,38,39}$.

Um inquérito nacional 2008-2009 identificou ingestão diária energética mais elevada na população que referiu usar açúcar de mesa, quando comparada às pessoas que só usam adoçantes artificiais $^{20}$. Em São Paulo, na comparação entre usuários e não usuários de adoçantes, a densidade energética dietética teve valores menos expressivos entre os que usavam o produto; todavia, no que se referiu ao consumo energético total e de macronutrientes (carboidratos, gorduras e proteínas), não houve diferenças ${ }^{40}$. Estes achados podem ter relação com os de Geraldo e Silva ${ }^{22}$, cujos entrevistados disseram usar adoçantes para compensar posterior ingestão de alimentos mais calóricos. Também pode relacionar-se com os de Ruanpeng et al. ${ }^{39}$, que informam ser autores da primeira meta-análise que associa o consumo regular de refrigerante artificialmente adoçado ao aumento geral do risco de sobrepeso e obesidade.

Hoffmann et al. ${ }^{38}$ observaram que tanto uma alimentação excessivamente rica em glicose quanto o uso de adoçantes dietéticos possuem mecanismos orgânicos particulares que predispõem seus usuários ao aparecimento de problemas metabólicos que podem desencadear o surgimento de obesidade e/ou diabetes e, por esse motivo, os autores aconselharam moderação no uso de ambos os produtos. 
O uso indiscriminado de adoçantes dietéticos é preocupante bem como a disseminação destes produtos em alimentos variados, até nos que já contêm açúcar ou nos lácteos acrescidos de lactase, reação que origina glicose, cuja ingestão é desaconselhável a diabéticos. Assim, o uso de adoçantes dietéticos nestes tipos de produtos seria dispensável. Tais informações técnicas oferecem vantagens a consumidores e fabricantes de produtos alimentícios. A divulgação de informações de cunho técnico também auxilia no controle de riscos à saúde, podendo ampliar o diálogo entre a vigilância sanitária, a população e os produtores de alimentos.

Sobre as condições de saúde dos usuários de adoçantes dietéticos no presente estudo, a hipertensão foi a mais prevalente das patologias autorreferidas, seguida por: dislipidemia, depressão e diabetes. Entre os homens, a depressão revelou-se em maior proporção do que a diabetes, achado que atrai a atenção para a necessidade de realização de pesquisas envolvendo tal temática. $\mathrm{Na} A B / S U S$ como um todo, também a hipertensão foi em maior proporção, seguida de: dislipidemia, depressão e diabetes ${ }^{27}$.

Estudos supõem haver busca pelo uso de adoçantes dietéticos por portadores de hipertensão arterial. No estudo de Cotta et al. ${ }^{4}$, a substituição do açúcar pelo adoçante artificial por pessoas com hipertensão arterial foi de $15,40 \%$. Outro estudo com portadores de hipertensão arterial internados em um hospital da Região Centro-Oeste estimou a prevalência no uso de adoçantes em $12,28 \%{ }^{41}$.

Entre os usuários de adoçantes, mais de 40,0\% afirmaram ter recebido diagnóstico de dislipidemia. A relação entre o uso de adoçantes dietéticos e o perfil lipídico requer investigação. Segundo Bruyère et al. ${ }^{9}$, a maioria dos estudos observacionais não indicou efeitos dos adoçantes sobre o perfil lipídico; outros estudos relataram a substituição de açúcares por aspartame com redução nas concentrações plasmáticas de triglicérides, porém esses pesquisadores consideraram ser esses dados muito limitados para conclusões sobre o efeito benéfico do aspartame no perfil lipídico humano. Neste estudo, encontrou-se um menor percentual de referência a ter diabetes comparado ao dos que declararam não ter a doença $(61,1 \%)$. Resultados que corroboram com o estudo de Geraldo e Silva ${ }^{22}$, no qual os usuários de adoçantes dietéticos não diabéticos também eram a maioria $(90,2 \%)$. Cotta et al. ${ }^{4}$ verificaram substituição do açúcar por adoçantes artificiais em 90,0\% dos diabéticos. 0 uso dos edulcorantes sacarina sódica e ciclamato de sódio predominou ${ }^{22,29}$. Estes edulcorantes parecem ser os preferidos pelas populações estudadas, inclusive hipertensos, mas, devido ao sódio que contêm, a falta de informação pode representar um fator de risco à saúde destes últimos usuários.

Como visto, os resultados encontrados, em ambos os sexos, apontam para percentuais significantes de uso de adoçantes por pessoas que têm diagnóstico médico de depressão. Indivíduos com depressão tendem a uma menor adesão às orientações nutricionais para evitar o consumo de doces e açúcares ${ }^{42}$. Constata-se a necessidade de investigar a relação entre a ingestão frequente de bebidas contendo adoçantes dietéticos e o aumento nos riscos de depressãa ${ }^{43}$.

A autoavaliação da saúde neste estudo demonstrou maior indicação de saúde boa ou nem ruim nem boa, todavia encontrou-se entre as mulheres percentuais semelhantes de referência a saúde ruim e muito boa. Em Guibu et al. ${ }^{27}$, mais de $55 \%$ dos usuários da AB/SUS avaliaram sua saúde como boa ou muito boa, em quase todas as regiões, exceto no Nordeste $(47,5 \%)$, onde $42,1 \%$ avaliaram como nem boa nem ruim. Considera-se que a escolaridade exerce efeitos sobre a autoavaliação do estado de saúde, na medida em que o indivíduo de maior escolaridade apresenta melhor percepção da própria saúde, sendo maior a prevalência de cuidados em realizar exames médicos preventivos com o aumento dos anos de estudo ${ }^{44}$. No presente estudo, os que se declararam analfabetos foram cerca de $11,4 \%$ das mulheres e $13,3 \%$ dos homens.

Constatou-se que a prescrição de adoçante dietético é bem limitada, pois a maioria $(54,3 \%)$ dos usuários desses produtos declarou não ter recebido prescrição, tampouco orientação para o uso. Entre os que receberam prescrição, o médico foi o principal prescritor e o nutricionista, em proporção bem menor. Essa questão é relevante, face às recomendações existentes, entre as quais o CFN recomenda indicação clínica e orientação para o uso adequado ${ }^{17}$. Mas a preferência pelo sabor doce parece inata no ser humano. A busca por este sabor, aliada ao desejo de evitar ingestão de calorias proporcionadas pelos açúcares, pode estar relacionada à ampliação do uso de adoçantes 9 .

A literatura traz indicativos de que o uso dos adoçantes dietéticos não pode ser indiscriminado e requer cuidados dos profissionais de saúde e da instituição de regulação e vigilância sanitária. Mas é importante ressaltar que não se encontram nos rótulos os teores de edulcorantes presentes em cada produto alimentício, o que impossibilita o cálculo destes pelos nutricionistas. Consequentemente, não se pode determinar a quantidade ingerida pelos usuários, em certo período.

O consenso entre especialistas é que mais estudos são necessários para informar à sociedade sobre possiveis riscos e eventuais benefícios desses produtos ${ }^{36}$. Há que se considerar também as descobertas sobre falhas nos rótulos de produtos alimentícios ${ }^{45,46}$, o que também pode constituir risco à saúde uma vez que denota desacordo dos rótulos com a legislação sanitária ${ }^{47}$, podendo influenciar numa escolha equivocada por parte do consumidor.

\section{CONCLUSÕES}

O estudo evidenciou largo uso de adoçantes dietéticos entre os usuários da AB/SUS. Em face das questões para a saúde que o uso de adoçantes dietéticos suscita - inclusive indicativas de riscos -, sugere-se moderação no uso desses produtos, enquanto não se tem respostas mais conclusivas sobre a sua inocuidade. Por essa razão, defende-se ações e instrumentos de regulação e vigilância sanitária orientados ao seu uso racional.

A ampliação dos esforços em investigações científicas sobre o tema também deve ser considerada como um investimento em proteção da saúde, especialmente dos grupos mais vulneráveis como as crianças, gestantes, idosos e portadores de determinadas patologias.

Possíveis limitações do estudo incluem o fato de não ser interrogada a preferência por tipos de adoçantes, dado útil para 
prescrições nutricionais, mas não investigado em razão de características do estudo e sua população. Também, não foi possível investigar o estado nutricional, face à crescente prevalência de excesso de peso no país, o que parece induzir ao uso de adoçantes. Ademais, a amostra constituída de usuários da $A B / S U S$ presentes nos serviços, quando possivelmente buscavam atendimento para algum problema de saúde, pode ser considerada um fator influenciador nos resultados, posto que pode se refletir sobre certas características dos usuários e perfil epidemiológico, com elevados percentuais de referências a doenças/ condições crônicas possivelmente superestimados, diferentemente da população geral.

\section{REFERÊNCIAS}

1. Malta DC, França E, Abreu DMX, Perillo RD, Salmen MC, Teixeira RA et al. Mortality due to noncommunicable diseases in Brazil, 1990 to 2015, according to estimates from the global burden of disease study. Sao Paulo Med J. 2017;135(3):213-21. https://doi.org/10.1590/1516-3180.2016.0330050117

2. Ministério da Saúde (BR). Termo de compromisso $\mathrm{N}^{\circ} 5$, de 26 de novembro de 2018. Termo de compromisso que firmam entre si a união, por intermédio do Ministério da Saúde, Agência Nacional de Vigilância Sanitária (Anvisa), Associação Brasileira das Indústrias da Alimentação (ABIA), Associação Brasileira das Indústrias de Refrigerantes e de Bebidas Não Alcoólicas (ABIR), Associação Brasileira das Indústrias de Biscoitos, Massas Alimentícias e Pães \& Bolos Industrializados (Abimapi) e Associação Brasileira de Laticínios (Viva Lácteos) para o estabelecimento de metas nacionais para a redução do teor de açúcares em alimentos industrializados no Brasil. Diário Oficial União. 27 nov 2018.

3. Almeida JZ, Carvalho KM, Sampaio HAC. Adoçantes artificiais: interrelações positivas e negativas com as doenças crônicas não transmissíveis. Rev Bras Nutr Clin. 2005;3(2):77-82.

4. Cotta RMM, Schott M, Azeredo CM, Franceschini SCC, Priore SE, Dias G. Hábitos e práticas alimentares de hipertensos e diabéticos: repensando o cuidado a partir da atenção primária. Rev Nutr. 2009;22(6):823-35. https://doi.org/10.1590/S1415-52732009000600004

5. Oliveira PB, Franco LJ. Consumo de adoçantes e produtos dietéticos por indivíduos com diabetes mellitus tipo 2, atendidos pelo sistema único de saúde em Ribeirão Preto. Arq Bras Endocrinol Metab. 2010;54(5):455-62. https://doi.org/10.1590/\$0004-27302010000500005

6. Associação Brasileira de Indústrias de Alimentos para Fins Especiais e Congêneres - Abiad. Peso: um estudo exclusivo do consumo brasileiro por níveis de peso. São Paulo: Associação Brasileira de Indústrias de Alimentos para Fins Especiais e Congêneres; 2011[acesso 24 out 2014]. Disponível em: http://www.abiad.org.br

7. Natividade DP, Rodrigues DCGA, Vieira VS. Xenobióticos: frequência da inserção na dieta dos adoçantes artificiais com destaque para o aspartame, ciclamato de sódio e sacarina sódica: possíveis efeitos adversos. Rev Praxis. 2011;3:(5):71-6. https://doi.org/10.25119/praxis-3-5-982

8. Halldorson TI, Strom M, Petersen SB, Oliven SF. Intake of artificially sweetened soft drinks and risk of preterm delivery: a prospective cohort study in 59,334 danish pregnant women. Am J Clin Nutr. 2010;92(3):626-33. https://doi.org/10.3945/ajcn.2009.28968

9. Bruyère $\mathrm{O}$, Ahmed $\mathrm{SH}$, Atlan $\mathrm{C}$, Belegaud $\mathrm{J}$, Bortolotti M, Canivenc-Lavier MC et al. Review of the nutritional benefits and risks related to intense sweeteners. Arch Public Health. 2015;73:1-10. https://doi.org/10.1186/s13690-015-0092-x

10. Torloni MR, Nakamura UM, Megale A, Sanchez VHS, Mano C, Fusaro AS et al. O uso de adoçantes na gravidez: uma análise dos produtos disponíveis no Brasil. Rev Bras Ginecol Obstet. 2007;29(5):267-75. https://doi.org/10.1590/S0100-72032007000500008

11. Nettleton JA, Lutsey PL, Wang Y, Lima JA, Michos $E D$, Jacobs Jr DR. Diet soda intake and risk of incident metabolic syndrome and type 2 diabetes in the multi-ethnic study of atherosclerosis (MESA). Diabetes Care. 2009;32(4):688-94. https://doi.org/10.2337/dc08-1799

12. Suez J, Korem T, Zeevi D, Zilberman-Schapira G, Thaiss CA, Maza $O$ et al. Artificial sweeteners induce glucose intolerance by altering the gut microbiota. Nature. 2014;514:181-6. https://doi.org/10.1038/nature13793

13. Kimata H. Anaphylaxis by stevioside in infants with atopic eczema. Allergy. 2007;62(5):565-6. https://doi.org/10.1111/j.1398-9995.2007.01317.x

14. American Dietetic Association - ADA. Position of the american dietetic association: use of nutritive and nonnutritive sweeteners. J Am Diet Assoc. 2004;104(2):255-75. https://doi.org/10.1016/j.jada.2003.12.001

15. Gardner C. Nonnutritive sweetners: current use and health perspectives: a scientific statement from the american heart association and the american diabetes association. Diabetes Care. 2012;35(8):1798-808. https://doi.org/10.2337/dc12-9002

16. Saunders C, Padilha PC, Lima HT, Oliveira LM, Queiroz JA, Theme MLM. Revisão de literatura sobre recomendações de utilização de edulcorantes em gestantes portadoras de diabetes mellitus. Femina. 2010;38(4):179-84.

17. Conselho Federal de Nutricionistas - CFN. Recomendação CFN N ${ }^{\circ}$ 3, de 29 de fevereiro de 2016. Sucralose. Brasília: Conselho Federal de Nutricionistas; 2016[acesso $14 \mathrm{abr}$ 2017]. Disponível em: http://www.cfn.org.br/index.php/ recomendacao-cfn-no-32016-sucralose/

18. Costa EA, Souto AC. Área temática de vigilância sanitária. In: Paim JS, Almeida Filho N. Saúde coletiva: teoria e prática. Rio de Janeiro: MedBook; 2014. p. 369-96. 
19. Costa EA. Fundamentos da vigilância sanitária. In: Costa EA, organizador. Vigilância sanitária: temas para debate. Salvador: Universidade Federal da Bahia; 2009. p. 11-36.

20. Monteiro LS, Hassan BK, Rodrigues PRM, Yokoo EM, Sichieri R, Pereira RA. Use of table sugar and artificial sweeteners in Brazil: national dietary survey 2008-2009. Nutrients. 2018;10(3):1-11. https://doi.org/10.3390/nu10030295

21. Zanini RV, Araújo CL, Martínez-Mesa J. Utilização de adoçantes dietéticos entre adultos em Pelotas, Rio Grande do Sul, Brasil: um estudo de base populacional. Cad Saúde Pública. 2011;27(5):924-34. https://doi.org/10.1590/S0102-311X2011000500010

22. Geraldo APG, Silva MEMP. Nonnutritive sweeteners in Brazil: current use and associated factors. J Hum Growth Dev. 2016;26(3):297-306. https://doi.org/10.7322/jhgd. 122760

23. Ministério da Saúde (BR). Portaria $N^{\circ} 2.077$, de 17 de setembro de 2012. Institui a pesquisa nacional sobre acesso, utilização e promoção do uso racional de medicamentos no Brasil (PNAUM). Diário Oficial União. 18 set 2012.

24. Mengue SS, Bertoldi AD, Boing AC, Tavares NUL, Pizzol TSD, Oliveira MA et al. Pesquisa nacional sobre acesso, utilização e promoção do uso racional de medicamentos (PNAUM): métodos do inquérito domiciliar. Rev Saúde Pública. 2016;50(Supl.2):1-11. https: / /doi.org/10.1590/s1518-8787.2016050006156

25. Álvares J, Alves MCGP, Escuder MML, Almeida AM, Izidoro JB, Guerra JAA et al. Pesquisa nacional sobre acesso, utilização e promoção do uso racional de medicamentos: métodos. Rev Saúde Pública. 2017;51(Supl.2):1-9. https://doi.org/10.11606/S1518-8787.2017051007027

26. Teixeira PM. Sobre o significado da significância estatística. Acta Med Port. 2018;31(5):238-40. https://doi.org/10.20344/amp.9375

27. Guibu IA, Moraes JC, Guerra Junior A, Costa E, Acúrcio FA, Costa $\mathrm{K}$ et al. Main characteristics of patients of primary health care services in Brazil. Rev Saúde Pública. 2017;55(Supl.2):1-13. https://doi.org/10.11606/S1518-8787.2017051007070

28. Ministério da Saúde (BR). Vigitel Brasil 2016: vigilância de fatores de risco e proteção para doenças crônicas por inquérito telefônico. Brasília: Ministério da Saúde; 2017.

29. Guerra TRB. Adoçantes e doenças crônicas: revisão de literatura. Cad Estudos Pesq. 2019;23(49):24-31.

30. Zanini RV. Prevalência de utilização de adoçantes dietéticos: um estudo de base populacional [dissertação]. Pelotas: Universidade Federal de Pelotas; 2010.

31. Rother KI, Sylvetsky AC, Walter PJ, Garraffo HM, Fields DA. Pharmacokinetics of sucralose and acesulfame-potassium in breast milk following ingestion of diet soda. $J$ Pediatr Gastroenterol Nutr. 2018;66(3):466-70. https://doi.org/10.1097/MPG.0000000000001817

32. Brugnera VF, Baruffi R, Panatto E. Utilização dos adoçantes durante a gestão e lactação. Pindorama. 2012;2(2):1-13.

33. Araújo JR, Martel F, Keating E. Exposure to non-nutritive sweeteners during pregnancy and lactation: impact in programming of metabolic diseases in the progeny later in life. Reprod Toxicol. 2014;49:196-201. https://doi.org/10.1016/j.reprotox.2014.09.007

34. Sylvetsky AC, Greenberg M, Zhao X, Rother KI. What parents think about giving nonnutritive sweeteners to their children: a pilot study. Int J Pediatr. 2014;2014:1-5. https://doi.org/10.1155/2014/819872

35. Viane J. Consumer behaviour towards light products in Belgium. Brit Food J. 1997;99(3):105-13. https://doi.org/10.1108/00070709710168941

36. European Food Safety Authority - EFSA. Report of the meetings on aspartame with national experts question. EFSA Technical Report. 19 maio 2010.

37. Azad MB, Abou-Setta AM, Chauhan BF, Rabbani R, Lys $J$, Copstein L et al. Nonnutritive sweeteners and cardiometabolic health: a systematic review and meta-analysis of randomized controlled trials and prospective cohort studies. CMAJ. 2017;189(28):E929-39. https://doi.org/10.1503/cmaj.161390

38. Hoffmann B, Ronan G, Haspula D. Why zero-calorie sweeteners can still lead to diabetes, obesity: common artificial sweeteners shown to change how the body processes fat and energy. Faseb J. 2018;32(1 Supl.1).

39. Ruanpeng D, Thongprayoon C, Cheungpasitporn W, Harindhanavudhi T. Sugar and artificially sweetened beverages linked to obesity: a systematic review and meta-analysis. QJM. 2017;110(8):513-20. https://doi.org/10.1093/qjmed/hcx068

40. Tavares CF. Densidade energética da dieta e ingestão energética total segundo consumo de adoçantes e ou alimentos procesados com adoçantes [dissertação]. São Paulo: Universidade de São Paulo; 2013.

41. Weisseheimer FL. Incidência de hipertensão arterial em uma capital brasileira: estudo de base populacional [dissertação]. Cuiabá: Universidade Federal de Mato Grosso; 2011.

42. Jacondino CB, Closs VE, Gomes I, Schwanke CHA. Adesão à dieta por idosos com síndrome metabólica assistidos na estratégia saúde da família: frequência e associação com depressão. Sci Med. 2016;26(3):1-11.

43. Guo X, Park Y, Freedman ND, Sinha R, Hollenbeck AR, Blair A et al. Sweetened beverages, coffee and tea and depression risk among older US adults. PLoS One. 2014;9(4):1-7. https://doi.org/10.1371/journal.pone.0094715

44. Barata RB. Como e por que as desigualdades sociais fazem mal à saúde. Rio de Janeiro: Fundação Oswaldo Cruz; 2016.

45. Silva NR, Falcone APM, Lima MS. Análise da adequação da rotulagem de produtos alimentícios regionais de acordo com a legislação no município de Cuité/PB. In: Anais do $23^{\circ}$ Congresso Brasileiro de Nutrição; São Paulo, Brasil. São Paulo: Associação Brasileira de Nutrição; 2014.

46. Garcia MR, Lopes RL, Daiuto ER. Conformidade de rótulos de alimentos consumidos por crianças e valor nutricional. In: Anais do $23^{\circ}$ Congresso Brasileiro de Nutrição; São Paulo, Brasil. São Paulo: Associação Brasileira de Nutrição; 2014. 
47. Agência Nacional de Vigilância Sanitária - Anvisa. Resolução RDC N² 259, de 20 de setembro de 2002. Aprova o regulamento técnico sobre rotulagem de alimentos embalados. Diário Oficial União. 21 set 2002.

Contribuição dos Autores

Paz BMS, Costa EA - Concepção, planejamento (desenho do estudo), aquisição, análise, interpretação dos dados e redação do trabalho. Todos os autores aprovaram a versão final do trabalho.

Conflito de Interesse

Os autores informam não haver qualquer potencial conflito de interesse com pares e instituições, políticos ou financeiros deste estudo.

Licença CC BY-NC atribuição não comercial. Com essa licença é permitido acessar, baixar (download), copiar, imprimir, compartilhar, reutilizar e distribuir os artigos, desde que para uso não comercial e com a citação da fonte, conferindo os devidos créditos de autoria e menção à Visa em Debate. Nesses casos, nenhuma permissão é necessária por parte dos autores ou dos editores. 